Instructions for authors, subscriptions and further details:

\title{
Análisis del "Enojo" del Varón en el Contexto de la Violencia contra las Mujeres para Trazar un Marco de Construcción de Responsabilidad
}

Luis Botello Lonngi ${ }^{1}$

1) Universidad Autónoma Metropolitana, México

Date of publication: February $21^{\text {st }}, 2017$

Edition period: June 2017 - October 2017

To cite this article: Botello, L.L. (2017). Análisis del "enojo" del varón en el contexto de la violencia contra las mujeres para trazar un marco de construcción de responsabilidad. Masculinities and Social Change,6(1),3961. doi: 10.17583/MCS.2017.1923

To link this article: http://doi.org/10.17583/MCS.2017.1923

\section{PLEASE SCROLL DOWN FOR ARTICLE}

The terms and conditions of use are related to the Open Journal System and to Creative Commons Attribution License (CC-BY). 
MCS - Masculinities and Social Change Vol. 6 No. 1 February 2017

pp. 39-61

\section{Analysis of Male "Anger" in the}

\section{Context of Violence against Women \\ in order to Design a Framework for \\ Construction of Responsibility}

Luis Botello Lonngi

Universidad Autónoma Metropolitana

\section{Abstract}

This article proposes a particular way of approaching male affection in the process of "anger" of men in the context of violence. In this framework, we proceed to the identification of the mechanisms that cause that the violence of men remains invariably. We intend to show how certain emotions emerge as an important source of interactive knowledge. We propose the analysis of these emotions as dynamic elements in the exchanges between subjects in their daily relationships, as well as in the establishment of autonomy and decision-making. Finally, we discuss how the emotional dimension in men can participate in the construction of what we call approximate responsibility to deal with the hegemonic male rules and to disable mechanisms of oppression.

Keywords: masculinity, emotions, fragmentation, anger, responsibility 
MCS - Masculinities and Social Change Vol. 6 No. 1 February 2017 pp. 39-61

\section{Análisis del "Enojo" del Varón en el Contexto de la Violencia contra las Mujeres para Trazar un Marco de Construcción de Responsabilidad}

Luis Botello Lonngi

Universidad Autónoma Metropolitana

\section{Resumen}

Este artículo plantea una manera particular de aproximarnos a la afectividad masculina en el proceso del "enojo" del varón en el contexto de la violencia. En este recorrido se identifican mecanismos que provocan que la violencia de los varones permanezca de manera invariable. Pretendemos mostrar cómo ciertas emociones emergen como fuente importante de conocimiento interactivo; se propone analizarlas como elementos dinámicos en los intercambios entre sujetos en sus relaciones cotidianas, así como en la conformación de autonomía y en la toma de decisiones. Finalmente se discute de qué manera en los varones la dimensión afectiva puede participar en la construcción de lo que denominamos responsabilidad aproximativa, para hacer frente a la normativa masculina hegemónica y desactivar mecanismos de opresión.

Palabras clave: masculinidad, afectividad, fragmentación, enojo, responsabilidad. 


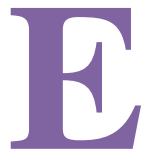

1 presente trabajo expone cuatro aspectos significativos de la investigación "Jóvenes y violencia de género" realizada en tres áreas urbanas de México en el 2015, en la que utilizamos metodología cualitativa a través de grupos de discusión con hombres jóvenes de 15 a 24 años. Nuestra intención es retomar estos aspectos que en nuestra opinión resultaron relevantes y provocadores para el aporte conceptual que queremos exponer en este escrito ${ }^{1}$.

Un aspecto importante que surgió en el discurso de los jóvenes fue el tema del "enojo" de los varones (Grupos 1, 2, 4, 5 y7) ${ }^{2}$. Para desarrollar una deconstrucción del enojo y su vínculo con la violencia se requiere hacer una precisión de la afectividad masculina. Por una parte, el enojo es una respuesta emocional que social y culturalmente suele ser tolerada, alentada y/o esperada del varón frente a diversas situaciones interactivas en las que se percibe atacado y/o amenazado, o como parte de una supuesta naturaleza masculina (Seidler, 2000). Por otra parte, nuestra intención no es hablar de las emociones en general, empresa que está más allá de los alcances del presente trabajo. Basta revisar la "Disertación sobre las pasiones" de Hume (2004), pasando por Descartes y Spinoza, hasta autores(as) más contemporáneos como Hansberg (1996), Vigotsky (1995), Gardner (2001), Eva Illouz (2007), para observar un campo teórico muy amplio ${ }^{3}$. Lo que nos interesa aquí es identificar aspectos de la afectividad vinculados con la construcción de género, y que estarían implicados significativamente en la generación de escenarios relacionales asimétricos.

Partimos de la tesis de que la vida emocional de los varones no está reprimida -visión arraigada en el sentido común- ya que las emociones no permanecen "contenidas" en espera de salir como si existieran obstáculos que las trabaran. En cambio, lo que sucede, coincidiendo en un sentido con la perspectiva de Hansberg (1996), es que las emociones están ligadas a objetos sociales mediadas por la normativa social. El patrón de relación de un varón muestra su vida emocional en el marco de una economía afectiva en operación. La masculinidad conforma la afectividad de tal manera que el mayor despliegue afectivo de los varones está ligado a objetos públicos de su entorno como el éxito, metas y logros socialmente valorados (Kaufman, 1989). En estos espacios la afectividad se pone al servicio de una identidad de género masculina estructurada en torno a un yo exterior, activo, creador de sentidos orientados por el reconocimiento social. Desde esta óptica las 
emociones son indicadores que permiten reconocer en qué aspectos sociales y personales están implicados los varones.

Durante el proceso interactivo los varones despliegan lo que denomino "discriminaciones emocionales pre-reflexivas", que son maniobras afectivas no intencionales que ligan afectividad a objetos sociales. Esta ligazón no se produce al azar, está orientada por coordenadas normativas masculinas. Las discriminaciones emocionales pre-reflexivas son mecanismos de desplazamiento, delegación y subyugación afectiva, que muestran que las emociones lejos de estar "reprimidas", se direccionan y delimitan según márgenes permitidos a partir de relaciones de poder establecidas. Estos mecanismos los describimos a continuación.

Para los varones existe un desplazamiento emocional hacia objetos del ámbito público (léase reconocimiento social, éxito, etc.) promovido por una economía afectiva masculina que se direcciona hacia escenarios sugeridos por los imperativos normativos genéricos. Este desplazamiento está presente en el imaginario social que otorga múltiples sentidos a los sujetos. En otro nivel, en los espacios íntimos, la economía afectiva opera organizando a los sujetos maniobrando de otra forma, pero acorde a la lógica anterior. En estos espacios, los varones suelen delegar en las mujeres para que ellas sean las responsables de los escenarios afectivos íntimos (por ejemplo, la atención a la afectividad en la vida en pareja, mantener redes en los espacios privados). En este escenario la mujer se convierte en "traductora emocional" de las propias emociones del varón. Cuando un varón no comparte en algún nivel comunicativo sus afectos íntimos se debe, como veremos más adelante, a que a través del silencio se evidencia también que está activa este tipo de economía afectiva. En el caso de un varón frente a otro varón se produce una variante del mecanismo: las emociones se subyugan a los imperativos racionales masculinos. Un varón se presenta frente a otro mediado por una racionalidad articulada con el género que otorga el margen de maniobra para ambos. Aquí emerge el componente heterosexual que otorga ordenación simbólica y lógica del mundo. Es por ello que entre los varones las emociones se amoldan, se contornean, se acomodan, subordinadas a los límites normativos heterosexuales que marcan delimitaciones al cuerpo y al contacto físico. La homofobia, por ejemplo, vista desde esta economía afectiva, es uno de los 


\section{MCS - Masculinities and Social Change, 6(1) 43}

efectos de la estrechez y no permisividad orientada por una raíz heterosexual estricta.

En estas discriminaciones emocionales pre-reflexivas (desplazar, delegar, subyugar) lo normativo actúa sobre la experiencia emocional fragmentándola; pero no de manera dispersa y arbitraria, sino con una lógica y orientación. Ésta es quizá la imagen más cercana a la vivencia afectiva por parte de los varones, donde las emociones tienen direccionalidad diferenciada que posibilitan modalidades de vínculos: fuertes, débiles y/o nulos según las delimitaciones dominantes de género. Desde esta óptica, en estos procesos interactivos se modularían las experiencias emocionales. En el escenario de relación de pareja, los aspectos emocionales como la empatía tendrían una marca "débil" y/o "inconexa" toda vez que las emociones estarían moldeadas al servicio de los imperativos masculinos que no incluyen tener presente ni implicarse en la experiencia emocional de las mujeres. Cabe decir, sin embargo, que en este proceso la normativa masculina es altamente funcional generando una ficción: la norma al fragmentar la experiencia emocional produce un beneficio para el sujeto al facilitar, por una parte, que se deshaga de lo supuestamente "innecesario" e "inútil", dejando a un varón libre y cercano de alcanzar lo deseado. Y, por otra parte, mantiene la ficción de estabilidad, de una idea de sí mismo sin interferencias, que lo aleja de colocarse en un lugar de vulnerabilidad social si se insinúa la implicación que tiene para sí y para la otra, la organización de su economía afectiva.

En este recorrido los varones niegan para sí mismos rutas y experiencias fuera de la órbita masculina dominante. Esta condición influye para que a un varón se le dificulte reconocer de qué manera otras personas viven sus experiencias y cómo elaboran, por ejemplo, sus temores, dolores, alegrías, sufrimientos, de manera diferente a la propia; experiencias emocionales que con frecuencia son irreconocibles para él. Situación que resuelve haciendo uso de un recurso social legitimado por la normativa dominante que consiste en devaluar aquello en lo que no está implicado y que no logra aprehender, lo que obstaculiza posibilidades de cercanía afectiva. Sin embargo, esta visión no pretende ser ni pesimista ni complaciente. Los varones no cuestionan estos mecanismos no porque sean "víctimas" del poder de la normativa masculina, sino porque obtienen beneficios tácitos cotidianos que les permiten mantener privilegios al implicarse personal y 
socialmente sólo en lo que consideran que tiene valor social; condición de poder que sitúa a la otra en la posición de atender lo faltante, lo no valorado, en el mantenimiento de la relación.

Toda esta condición de la afectividad masculina de la que hemos hablado, es clave para comprender la dinámica del enojo en el contexto de la violencia contra las mujeres.

\section{El Enojo del Varón y su Utilidad}

Para los varones el enojo es comprensible desde una razón instrumental. Me explico. Primero, sucede "algo" que le afecta al varón, a continuación, una espera y después la posibilidad de repararlo (que en el discurso de los jóvenes de los grupos de discusión lo expresan como "desquitarse", "vengarse" -Grupos 1, 2, 3 y 6- ). Es decir, sentir que algo te afecta, aguantarlo y saber que después se puede sacar y te podrás desquitar, es parte del mecanismo naturalizado que hace inteligible esta emoción. El enojo se convierte entonces en un mediador entre algo que afecta al varón y la posibilidad de repararlo. En este marco, "vengarse", "desquitarse" hace referencia a que el varón se percibe en una posición donde requiere compensar algo; vive una falta que traduce como desventaja en su espacio relacional. Pero lo central, como veremos enseguida, es que esta falta (y esta forma de codificarla) se activa en el marco interactivo con la Otra, y se resuelve a través de la violencia y no de otra manera.

El enojo del varón es un intento activo por resarcir una idea de sí mismo fragmentada. La interacción con una mujer que da cuenta de sí misma al verbalizar, exponer y ligar su vida emocional desde un marco afectivo de género diferente al propio, le devuelve al varón la imagen de su condición afectiva fraccionada, con ello "emerge" inintencionalmente su falta. La manera de interpretar la vida emocional de la otra también está orientada por la propia normativa masculina que devalúa formas distintas de economía afectiva.

A través del enojo -y al ser localizado el objeto social (mujer) que le otorgará la "reparación"- se busca un efecto tácito que no le devuelva un sí mismo fragmentado; se pretende afirmar una identidad a partir de imperativos dominantes masculinos: cohesión racional de las partes, estabilidad y delimitaciones definitivas del sí mismo. En efecto, lo que se 
pretende "reparar", en un acto real o fantaseado, es la sensación personal de unicidad, reintegración, totalidad y estabilidad. En este mecanismo, la práctica violenta busca un efecto definitivo de retribución que permita la sensación de control de un sí mismo no fragmentado, unificado y dominante. La práctica violenta simula garantizar de inmediato la compensación buscada. Pero ¿por qué se busca esa compensación a través de violentar a la otra, y no virar a otro escenario, por ejemplo, alejarse del objeto social que le devuelve un sí mismo no deseado? La razón no solo estriba en que en la interacción con la otra se activa la falta, sino porque ese es justamente el lugar donde se puede obtener la compensación. La práctica se produce donde ya existe un desequilibrio de poder, que requiere de ese mecanismo para actualizar y re-situar a los sujetos.

Esta ficción de reparación que "emerge" en la interacción está destinada a una repetición circular -implicada en la activación del círculo de la violencia-, porque la reparación buscada por el varón a través de la práctica reiterativa es un imposible constitutivo identitario, al no ser posible esa experiencia de completud buscada. No obstante, la promesa normativa masculina insiste en que sí es posible esa totalidad, y al ocultar la raíz de esa imposibilidad, genera que la práctica violenta sea "efectiva" porque simula que se obtiene la retribución buscada.

A través de este mecanismo se confirma la utilidad del objeto social (mujer) garantizando la circularidad cuando se active la falta. Cabría decir que el objeto se haría paulatinamente más propicio, mermando la capacidad de respuesta toda vez que la práctica busca una y otra vez - con su reiteración- la docilidad a la norma por parte del sujeto. Es decir, se pretende en cada acto, que la otra se coloque física y emocionalmente y acepte su lugar de desigualdad; buscando que las mujeres se amolden cada vez más con la menor resistencia posible. Por esta razón en mujeres que están expuestas a una dinámica de violencia es muy probable que vean poco a poco mermadas su autoestima y confianza en sus posibilidades de hacerle frente. Así, de continuar la exposición a la violencia, resulta más difícil salir de ella.

En el contexto de la violencia contra las mujeres tendríamos que definir el enojo como un mecanismo emocional de control social al servicio de la meta normativa dominante, que está legitimado por el patriarcado para que los varones reaccionen "justificadamente" si los descolocan de su posición 
central identitaria de dominio. Esta reacción emocional (enojo) activa el recurso de la violencia porque es un continuo de un mismo proceso que busca el cumplimiento de la idea patriarcal de "complementariedad", donde la mujer quedaría por debajo, cuidadora y al servicio del varón.

\section{EI Enojo como "Aliado"}

Teniendo en cuenta lo anterior, no se trata de que el hombre intente o haga todo lo posible por no enojarse, como solución estratégica, o que "respire hondo y cuente hasta diez" para evitar que derive en una práctica indeseable. Una perspectiva superficial sugeriría la búsqueda de opuestos, con la idea de que el varón evite a toda costa ese sentimiento "negativo", que se colme de ideas positivas y optimistas como lo sugerirían algunas tendencias psicologisistas, y más claramente como lo aconsejan los libros de superación personal. Esta lógica de alejarse de lo que ha sido etiquetado como negativo puede terminar revirtiéndose cuando nuestras buenas intenciones traducidas en fórmulas simplistas clasifican el mundo social en bueno y malo. Consideramos que lo que está en juego es la posibilidad de modificar el estatus del enojo y su recolocación como fuente de conocimiento interactivo con capacidad de trastocar la base en la que se sostiene.

Esta postura sugiere que los recursos emocionales que se han denominado "negativos", o, por el contrario, que se toleran socialmente como parte normalizada de una supuesta naturaleza masculina, no deberían desestimarse a priori en nuestra intención académica, personal, terapéutica, política, activista, etc., de desactivar una práctica indeseada. El recurso que oprime, localizado y analizado, debería ser nuestro principal "aliado", en el sentido que nos permite un conocimiento situado de los componentes en que se apoya una experiencia vital.

\section{Masculinidad, Autonomía y Responsabilidad}

Hasta aquí hemos tratado de explicar de qué manera la experiencia del enojo muestra la búsqueda del varón de una idea de sí mismo imposible de alcanzar. Este proceso pone al descubierto a un sujeto fuertemente "dependiente" del sistema normativo, condición que revierte la percepción 
social frecuentemente compartida de considerar a la "independencia" o su búsqueda como característica intrínseca en la definición de un sujeto varón. Lo que hemos revisado revela a un sujeto significativamente atado dependiente- a la normativa, y permite girar nuestra atención a los lugares desde dónde los varones dan cuenta de sí como sujetos autónomos, independientes.

Ser varón en el patriarcado es estar en un lugar favorecido y privilegiado para maniobrar relacionalmente, y se basa en la lógica de que un sujeto sea atendido mientras él atiende lo importante y valorado socialmente. La experiencia de ser independiente, autónomo, estaría marcada por este proceso, donde el grado de cumplimiento de los mandatos dominantes permite al varón operar con márgenes de autonomía, decisión y autoridad en la medida que se apropia de las reglas del sistema que le son favorables. Desde esta perspectiva funcional de la autonomía el varón puede dar cuenta de sí como sujeto "independiente", que conoce, se reconoce y utiliza las reglas del juego.

En este mecanismo la idea de responsabilidad queda circunscrita al imperativo dominante que la delimitada al mandato de "ser proveedor". Siguiendo a Emma (2005) una de las dimensiones de la responsabilidad la define como la capacidad de promover cambios, de producir efectos en la realidad social. Para nuestro tema de interés, la producción de estos efectos tendría que pasar por reconocer lo que estos implican para la otra. Entonces ¿qué lugar tiene la responsabilidad cuando el lugar de enunciación del varón está ligado a la normativa que otorga contenidos a su experiencia de autonomía, donde la responsabilidad estaría delimitada al cumplimiento del esquema de ser proveedor, ser atendido y permanecer lejano a los procesos de autonomía del otro(a)? Como veremos más adelante, la autonomía no es un lugar o un estado a donde llegue el sujeto, ni está delimitada por la experiencia individual, sino que es un proceso social que tensiona la libertad del sujeto en un entramado de relaciones de poder.

Retomando lo anterior existen aspectos que pueden favorecer el análisis de la experiencia afectiva ${ }^{4}$ para establecer una postura frente a la violencia contra las mujeres. A continuación, los explicamos. 


\section{Reenfocar la Revisión de las Emociones. La Afectividad del Varón Comprometida en Desactivar Mecanismos de Opresión}

Uno de los ámbitos que se ha trabajado de manera importante en el análisis de la masculinidad es el referente a la dimensión emocional (Kaufman, 1989; Browker, 1998; Seidler, 2000; Connell, 2003; Kimmel 1997)5. No obstante, cuando se cuestiona a algunos varones que trabajan en esta área profesional de cómo esta dimensión podría estar ligada a hacer frente a mecanismos que mantienen el dominio y la desigualdad, no siempre hay respuestas satisfactorias (Bonino, 2012). Se suele llegar a lugares comunes de que es conveniente que los hombres expresen sus emociones "reprimidas", que hablen de sus malestares, que los haría más cercanos; como si la finalidad fuese la expresión por sí misma, dejando de lado cómo el análisis de la afectividad de los varones podría favorecer la desactivación de dispositivos de opresión.

Esta óptica de que lo emocional está reprimido y que es desconocido por las personas, está relacionada con la concepción de que los seres humanos estamos constituidos por una suerte de esencia humana no "contaminada" por lo social, que está ahí dentro, oculta, en espera de ser descubierta, y que al hacerlo revelaría lo que "realmente" somos ${ }^{6}$. Visión que deja de lado cómo algunas emociones están presentes al permitir a los varones calcular, retomar experiencias anteriores, sopesar y evaluar una situación interactiva con consecuencias para sí mismo y para los demás.

Buscar la "esencia" de lo que somos para descubrir y expresar lo que ha estado oculto, también se relaciona con la extensa literatura comercial de "superación personal", que en el tema que nos ocupa, partiría de una idea central: existe un sujeto en falta por desconocimiento de sí mismo, que requiere de técnicas comunicativas individuales para lograr su crecimiento y liberarse de ataduras psicológicas. Desde esta óptica, la idea radica en que es necesario que los varones se den cuenta de esa riqueza personal que han desaprovechado al no poder expresar objetivamente el mundo emocional reprimido -ya que el "yugo" de la sociedad los ha enseñado de esta manera a ser hombres-, lo que permitiría cambiar la emoción negativa por una positiva, facilitando así alcanzar el bienestar? 
Esta perspectiva individualista aplicada al análisis de la masculinidad que llamaremos "emocionalista"-, es claramente conservadora, ya que si bien aborda un tema importante de incluir en el debate sobre la masculinidad $^{8}$, carece de un elemento clave: desde un enfoque igualitario de qué manera el componente emocional podría participar en desactivar algún mecanismo que genera subordinación. El que un varón exprese sus "emociones reprimidas", que "llore", no nos dice ni garantiza nada en realidad, políticamente hablando; quizá sea recomendable para él como catarsis individual de sus malestares. Por ello es preciso discutir si este tipo de perspectivas permiten desafiar en algún sentido una dinámica de dominación basada en género.

El análisis que se ha desarrollado en este escrito aporta información de cómo algunos mecanismos de la afectividad están al servicio de la desigualdad, ya que se activan para mantener en el varón, a través de oprimir a la otra, una idea ficticia de sí mismo. En este proceso los varones no toman en cuenta las consecuencias que tiene esta economía afectiva para la otra, las prácticas que la acompañan, los costos para sí mismo, ni los beneficios de dominación que obtienen.

En el trabajo grupal o individual terapéutico y/o reeducativo que se lleva a cabo con los varones, el manejo de la afectividad (desde esta perspectiva emocionalista) puede estar operando una tautología no reconocida: se realiza alguna actividad personal o grupal a través de la cual se presupone se identifica, emerge y se expresa una emoción, y eso observable que surge ahí confirma la existencia de esa emoción "reprimida". Es un "performance" donde el hecho de nombrarla y actuarla la crea; la actuación es lo que confirma la existencia de la emoción -mecanismo que Ashley Montague (1988) define como tendencia al pensamiento circular. En esta puesta en escena no cabe otro tipo de análisis porque ello sería frenar, intelectualizar, volver a "reprimir" y resistirse a liberarse personal o grupalmente de aquello reprimido que necesita ser expresado. De esta manera metodológicamente el sujeto queda atrapado y destinado a "liberarse" si no pone ninguna resistencia a dejar salir "su" emoción -con el casi probable dolor que ello implica por ahondar en "lo más escondido"-, sufrimiento que a su vez es señal inequívoca, objetiva y confirmatoria que se está por buen camino y que efectivamente hace falta que libere esa emoción "personal" para que "él”" sane. 
Esta perspectiva individualista alienta a que el varón se perciba permanentemente en falta y víctima del poder; necesitado de adquirir una competencia comunicativa personalizada y específica, alejándose de un escenario que incluya al otro(a), que posibilite el conocimiento de sí mismo desde una perspectiva relacional. Condición desde la cual se podría analizar cómo se van construyendo mecanismos de dominación -a veces evidentes y otras de manera más sutil ${ }^{9}$, donde las emociones se sedimentan corporal, comunicativa y moralmente estableciendo relaciones desiguales.

Siguiendo a Eva Illouz (2007) podemos llevar el debate a un plano social más amplio si tomamos en cuenta la funcionalidad que puede tener esta visión de la afectividad. Esta autora plantea que la vida emocional en el sistema neoliberal actual debería entenderse desde la lógica del intercambio, donde lo emocional pasa a ser un bien social negociable, no limitado al ámbito privado, que incorpora nuevas técnicas y sentidos que lo hacen atractivo, que proporciona nuevas formas de sociabilidad entre los sujetos. Desde esta perspectiva podemos aproximarnos a cómo se va construyendo un componente social novedoso entre los sujetos, una modalidad interesante de ser incorporada en las relaciones.

Se produce un estilo emocional cuando se formula una nueva imaginación interpersonal, es decir, una nueva manera de pensar la relación del yo con los otros y de imaginar sus posibilidades (...) según guiones imaginarios que dan sentido a la proximidad o la distancia sociales (Illouz, 2007, p. 24).

En nuestra opinión estas corrientes que trabajan la dimensión emocional de los varones, en el sentido anteriormente expuesto, generan una fuerte sospecha. Podrían estar siendo partícipes de la construcción de un capital emocional conservador al servicio de los mecanismos de desequilibrio del sistema, donde se conforma el paradigma de varones "sensibles", flexibles y emocionalmente acomodaticios, sin cambiar ni desafiar ninguna estructura de dominación. Para ellos el conocimiento, expresión, control y manejo de las emociones emergen como un componente más de los recursos comunicativos individuales de un patriarcado renovado. 


\section{La Autonomía en Espejo o cómo Evidenciar la Paradoja Identitaria del Varón}

Un aspecto presente en el proceso identitario del varón radica en no incorporar para sí aspectos femeninos de su contexto; mecanismo que favorece la idea de un sujeto varón socialmente diferenciado, valorado, reconocido, autónomo, independiente. Seidler (2000) nos recuerda que la definición predominante de autonomía, sustentada en el paradigma de la Modernidad, requiere deshacerse de lo que esté relacionado con el mundo femenino. La autonomía es una cuestión de voluntad y determinación para eliminar aspectos no valorados y estorbosos para los sujetos.

En los grupos de discusión los jóvenes varones de nuestro estudio expresaron que incluir algún aspecto femenino en sus vidas tenía efectos indeseables que pasaban por el cuerpo: "incluir algo femenino en ti se siente raro hasta en el cuerpo, cómo te diría... es como si te debilitara" (Grupo 5).

"No ser femenino" otorga contenido territorial subjetivo a los varones para vivir la diferencia respecto a las mujeres: es no ser lo otro, no dejarse influir por ello. Tiene como base la dicotomía que pretende mantener sin fisuras la idea de un sujeto varón independiente. No ser femenino emerge como un mecanismo de anulación subjetiva que intenta no reconocer la experiencia de la otra como equiparable a la propia.

En este sentido, la incorporación coyuntural por parte de los varones de algún aspecto considerado femenino en su contexto, tendría que ser visto críticamente debido a que es posible que los varones pudieran incorporar componentes de la feminidad sin que se modifique el desequilibrio de poder, en el sentido de que este mecanismo podría no atentar la base real de dominio que sostiene la dicotomía... sólo la modularía. Un ejemplo de ello son los varones emocionalistas que hemos definido en el apartado anterior, que no atentan contra ninguna estructura de dominación, pero que sí hacen suya la dimensión afectiva tradicionalmente relacionada a la feminidad ${ }^{10}$.

Este proceso donde se articula diferencia, impermeabilidad, dicotomía, cancelación subjetiva, nos permite girar nuevamente la atención a cómo se conforma un sujeto varón autónomo. La autonomía del varón no incluye tomar en cuenta la autonomía de la mujer con la que se relaciona. El proceso para que los varones se vivan como sujetos independientes está 
orientado por la normativa para controlar aquello que puede debilitarlos o amenazar, conformando un escenario donde la definición de su autonomía requiere imposibilitar procesos de autonomía de la otra, para que sea sostenible aquello que vive como autonomía. Sampson lo explica en términos más amplios y desafiantes "aun los grupos dominantes viven una mentira: su autonomía yace en su poder para construir otros no autónomos. Aún ellos dependen de estos otros, sin quienes su autonomía ilusoria se desvanecería" (Sampson, 1994, citado en Amuchástegui, 2003, p. 147). Desde esta óptica el varón depende del desequilibrio de poder en las prácticas cotidianas para poder dar cuenta de sí como un sujeto "autónomo". Por ello resulta indispensable revisar maniobras de poder en el proceso de autonomización de los varones para identificar en este camino cómo se ve comprometida la autonomía de las mujeres con las que interactúan.

Por otra parte, como hemos visto la conformación de esta idea de sujeto total es un imposible constitutivo identitario. Pero lo que hay que resaltar aquí es la insistencia de la norma hegemónica en su intento de lograr ese sujeto definitivo, insistencia que muestra también su propia vulnerabilidad como lo sugiere Judith Butler (2001), ya que la norma al requerir esa confirmación permanente, muestra que no es efectiva ni definitiva de una vez y para siempre. Identificar esta posibilidad, estos intersticios, esta característica de amoldamiento no concluyente a la norma, de posible ruptura, nos permite cuestionar esa ficción de la masculinidad dominante, y percibir a un sujeto que atraviesa y es atravesado por redes de significación no cerradas ni definitivas, con márgenes de mutabilidad. Emerge un sujeto con fisuras, inestabilidades y posibilidades de variabilidad... impensables para la lógica normativa, al abrir espacios que pueden fugarse de la órbita dominante.

En estos procesos tendrían que identificarse componentes que favorezcan la conformación de responsabilidad -entendida aquí como implicación en prácticas igualitarias- por parte de los varones. Cuestión que abordaremos a continuación. 


\section{Elementos para la Construcción de una Responsabilidad Aproximativa}

En este apartado sugerimos incluir lo que denomino responsabilidad aproximativa como un escenario que evidencie el componente afectivo para tensar lógicas que organizan el mundo interactivo en una dinámica violenta. Responsabilidad aproximativa es generar efectos en las relaciones cotidianas a través del reconocimiento de emociones mutuas, que permitan la conformación de habilidades para desafiar la normativa masculina dominante. La proximidad con la otra(o) es un escenario donde un sujeto evalúa, orienta y decide (consciente o pre-reflexivamente) una acción hacia una persona en específico ${ }^{11}$.

Los componentes histórico y evaluativo son relevantes en nuestra idea de responsabilidad. Histórico, ya que advierte lo importante de reconocerse como sujetos en proceso, resultado de convenciones, mandatos, consignas sociales, culturales, normativas que nos constituyen, y que si bien tienen la fuerza de determinar lo que somos, esto no sucede de manera cerrada, definitiva e invariable. Evaluativo, ya que revela mecanismos que permiten identificar una singularidad acerca de cómo se genera una disposición moral para "situar" al otro, qué lugar le otorgamos para que se despliegue un determinado abanico de acciones.

El componente evaluativo es reconocer que la afectividad está activa, no reprimida, y que favorece un determinado juicio y valoración de la relación $^{12}$. Y la historicidad nos remite a que esa valoración no surge de manera natural, espontánea ni ocurre siempre de la misma manera, está atada a mecanismos que la hacen cambiante en el transcurso de nuestra vida. De esta manera, la experiencia de "responsabilidad" por parte de los sujetos se conforma como resultado de la articulación de estos procesos. Escenario que nos indica que están presentes y en tensión múltiples significados que acompañan, dan contenido y definen una experiencia.

Por otra parte, un aspecto a tomar en cuenta en la construcción de responsabilidad aproximativa, estaría dado por lo encontrado en el discurso de los jóvenes del estudio, ya que nos permite identificar un mecanismo de dominación que en nuestra opinión frena significativamente la conformación de este tipo de responsabilidad. Existe una constante en el discurso de los jóvenes de nuestro estudio que afirma que las inseguridades y dudas del varón en la vida privada se deben de manejar de manera 


\section{Botello-Análisis del "Enojo" del Varón}

individual y en silencio: "uno no tiene que ir contando por ahí sus cosas, ¿no?, uno se guarda sus cosas personales para uno, calladito, así no te anda criticando nadie...no sé si esté bien o mal, pero por lo menos no te atacan" (Grupo 7). Esto coincide con varios autores que afirman que la vivencia de la masculinidad plantea no expresar aspectos íntimos porque se pretende evitar la experiencia de vulnerabilidad y vergüenza (Kimmel 1997). Por su parte Seidler (2000) nos recuerda que lo que queda sin decir de los varones es igualmente importante para entender cómo se relacionan, y las consecuencias de ello. Esta característica nos remite a un espacio donde se dirime el poder desde un ángulo poco explorado en el análisis de la masculinidad: el silencio, que es un mecanismo que en realidad sí habla. El silencio es el resultado de que la normativa masculina ya ha operado, es un indicador "exitoso" de la dominación en el sujeto. El silencio muestra aquí su utilidad, es condición necesaria para que el varón evalúe individualmente y sin alteraciones una situación interactiva; mecanismo que permite a la norma asegurar su permanencia. En este sentido, el silencio emerge como componente idóneo para mantener y reeditar relaciones desiguales. Schreiter (1998) afirma que en las dinámicas de dominación y violencia el silencio entre los sujetos tiene la función de reforzar la opresión.

El "monologismo" al que hace referencia Bajtín (1982), nos estaría hablando de esta característica discursiva que, en clave de género, podríamos definirla como un dispositivo comunicativo, dominante y cerrado que otorga seguridad y control a los varones. Su contraparte es la irrupción de "voces", una polifonía (Bajtín \& Voloshinov, 1992), confluencia de voces en conflicto con el discurso hegemónico que pretende erigirse como la única voz autorizada para determinar el significado de una experiencia. Esta cualidad permite definir lo "dialógico" (Bajtín, 1982) como condición discursiva para disputar el sentido de una experiencia y dar cuenta de ella ${ }^{13}$. La responsabilidad de la que hablamos tiene por tanto un rostro dialogante, no es una tarea individual para los varones en solitario para identificar las coordenadas de género que están operando en su cotidianidad $^{14}$.

Siguiendo a Bowker (1998), Gilligan (1982), Seidler (2000), la responsabilidad estaría entonces comprometida con identificar y desafiar los parámetros dominantes que no aceptan la dimensión afectiva como fuente de conocimiento válida. La responsabilidad aproximativa sugiere 
que las emociones ligadas al mandato masculino hegemónico estarían frenando la conformación de emociones éticas que tengan presente al otro(a). Desde esta perspectiva, la empatía, que es una habilidad emocional a tener en cuenta en escenarios violentos, conlleva descifrar señales de comportamiento, deseos, afirmaciones y sentimientos del otro(a)... y conocimiento y reconocimiento de estas señales en uno mismo. Implica tener presente la propia vulnerabilidad y la del otro(a). La empatía es fundamentalmente un ejercicio de interpretación situado, que se va habilitando para generar una respuesta favorable hacia otro (y por lo tanto con efectos en la relación).

Las emociones al permitir contar con pautas orientativas para evaluar una relación, habilitan moral, corporal y discursivamente al sujeto para desarrollar prácticas. Esta característica de cómo opera la afectividad nos indica que las emociones están ligadas a objetos sociales de manera prereflexiva, y que participan en conformar una disposición en la relación, ya sea (en el tema que nos ocupa) para desafiar, fisurar o reafirmar el mandato hegemónico masculino individualista. La idea de responsabilidad que manejamos marcaría una ruta diferente al proceso del enojo: tensa esta emoción descentrándola de la normativa dominante a la que ha estado atada, que puede derivar en la configuración de una emoción ética que toma en cuenta qué le pasa a la otra y responder a ello.

El análisis de las emociones implica discutir cómo nos relacionamos con el otro, cómo tratamos a los demás, es analizarnos interactivamente en el entendido que los escenarios emocionales "son rasgos constitutivos no de los individuos sino de las relaciones" (Gergen, 1996, p. 259). Nuestra postura no proviene de un decreto de "deber ser" -que corre el riesgo de convertirse en un discurso políticamente correcto de los varones-, sino en una óptica que pone acento en hacer visible maniobras emocionales como parte de las dinámicas de poder.

Finalmente queremos comentar que en los grupos de discusión los varones también mostraban discursos híbridos -donde coexistían elementos dominantes frente a otros que resistían su lógica-, lo que permite observar contradicciones en las formas de vivir la masculinidad; es decir, ya operan formas de resistir la versión dominante masculina. Pero aquí más que hablar de "nuevas masculinidades", "nuevos hombres" o "masculinidades emergentes", lo que es importante señalar es que una visión crítica de la 
economía afectiva puede ampliar los escenarios que desafían la dominación. Es poner el acento en las condiciones que hacen posible dar cuenta de sí mismo en relación con la otra, desmarcándose de parámetros con los que se ha aprendido a menospreciar, posponer, descartar y cancelar componentes significativos de la propia experiencia y la de los demás.

Existen muchas voces en diferentes latitudes, activistas, terapeutas, académicas(os) y organismos internacionales que sostienen que la violencia ejercida por los varones contra las mujeres tendría que ser definida y vivida como una "elección" en un entramado de relaciones de poder. Con este escrito pretendemos colaborar en dar sustento a esta perspectiva.

\section{Apunte para una Política Pública}

El tema de la responsabilidad por parte de los varones desde el análisis que aquí se sugiere, podría ser parte los insumos para repensar la elaboración de políticas públicas destinadas a la prevención. Sugerimos que los contenidos de las acciones para construir responsabilidad aproximativa pueden dividirse en tres dimensiones:

Revisión de la autonomía en espejo. Revisar procesos de autonomía en la vida cotidiana de los varones junto con los procesos de autonomía de las mujeres con las que el varón convive. Emprender este proceso junto con las mujeres en un marco de diálogo que permita reflexionar sobre los intercambios explícitos e implícitos durante los trayectos de vida de mujeres y hombres. Que identifiquen conflictos, contradicciones, subordinaciones, confluencias, sinergias, y tomar posturas frente a ello.

Las emociones fuente de conocimiento relacional. Resignificación de la dimensión afectiva que desafíe al soliloquio normativo, que incluya la construcción de emociones éticas donde lo dialógico impere frente a lo hegemónico. Desarrollar estrategias que pongan en el centro la ruptura del monologismo, y la construcción de empatía como habilidad social emocional a desarrollar a través de procesos educativos comunitarios, o transversalizado en el currículo para escenarios escolares.

Perspectivas cambiantes frente a certeza normativa. Permeabilizar las fronteras simbólicas femenino/masculino que permite la fluidez de género. Superar al género como parámetro orientativo vital de certidumbres. Frente a la dicotomía... la multiplicidad de prácticas que desacrediten la ficción de 


\section{MCS - Masculinities and Social Change, 6(1) 57}

un varón delimitado, completo y definitivo, por uno abierto, parcial, mutable.

Frente a una práctica hegemónica evidenciar la variabilidad de prácticas posibles, experiencias existentes o imaginadas fuera de lo normativo. A la manera de Bruner (1986), subjuntivizar nuestra realidad interactiva: trasformar conjuntamente el modo indicativo (yo soy, yo quiero, yo puedo) por el modo subjuntivo (yo sería, yo podría, yo quisiera), que permita enfrentar la mirada normalizadora de "lo definitivo" por "lo posible". Provocar imaginar escenarios abiertos para resituarnos frente a los mandatos monolíticos de género.

\section{Notas}

1 Agradezco las largas y clarificadoras discusiones con Natalia Biencinto López y Luis Bonino Méndez, que permitieron que este trabajo se nutriera y reorientara significativamente.

2 Se utiliza el término "varón" por el de "hombre", evitando el uso androcéntrico del término "hombre" como sinónimo de "humanidad". Aunque este término también presenta inconvenientes, esperamos que pueda cumplir con esta intención.

${ }^{3}$ Para un interesante recorrido antropológico de las emociones ver Le Breton (2012), donde otorga un estatus importante al análisis de las relaciones para interpretar la afectividad de las sociedades y de los individuos en particular. Por su parte, Ramírez Goicoechea (2001), aborda el tema de las emociones desde una perspectiva interdisciplinar para proponer una teoría de la complejidad de lo emocional. Enciso y Lara (2014), desarrollan un estudio de las emociones al interior de las Ciencias Sociales durante el siglo XX y lo enmarcan desde siete aproximaciones: El Socioconstruccionismo, la Psicología Social Discursiva, los Estudios Culturales de las Emociones, las Emocionologías, la Sociología Interpretativa, la Sociolingüística de las Emociones, y los Estudios Feministas de las Emociones.

${ }^{4}$ Nuestra intención, como se verá enseguida, es incluir la afectividad como componente de análisis problematizador respecto al papel de los varones para hacer frente a la violencia. Con este movimiento se politiza un componente que aparentemente se circunscribe en la esfera individual, para situarlo en el ámbito social y susceptible de incluirse en la definición de política pública.

${ }^{5}$ En México, Ramírez, Gutiérrez y Cázares. (2015), preguntaron a profesionales que trabajan en el tema de masculinidad -desde la academia, organizaciones de la Sociedad Civil y a funcionarios de la administración pública-, sobre los temas que más han trabajado en este terreno: las emociones están en primer lugar, seguida por violencia de género. Y mencionan que el tema-problema más importante identificado como objeto de política pública es la violencia de género. 


\section{Botello-Análisis del "Enojo" del Varón}

${ }^{6}$ La corriente teórica del Construccionismo Social ha criticado radicalmente la existencia de un supuesto esencialista que constituya al sujeto independiente de lo social e histórico. Para profundizar en este debate ver a Potter (1998), Ibáñez (1994), Gergen (1996).

7 Illouz (2007) analiza el surgimiento contemporáneo de una narrativa de autorrealización donde se busca una "mayor compatibilidad entre la psicología y el punto de vista moral" de que las personas pueden y deben labrar su destino de forma individual. De hecho, para esta autora la autorrealización del yo se va desplazando para convertirse en sinónimo de salud, lo que favorece a que prolifere la identificación de "conductas no saludables" emocionalmente, "disfunciones" que requieren ser abordadas desde el "modelo e ideal de la vida plenamente autorrealizada".

${ }^{8}$ La dimensión afectiva en el sistema patriarcal ha estado devaluada y delegada a las mujeres, los débiles y subordinados, y no se le considera legítima como fuente de conocimiento. En este sentido, incluirla en el análisis de la masculinidad desde una visión crítica, implica otorgarle otro estatus, lo que podría derivar en reposicionar a las emociones como componentes activos en las dinámicas de poder para evidenciar y favorecer elementos subversivos de las interacciones que desafíen al patriarcado.

9 Para Bonino (1995) existen dispositivos "sutiles" favorecedores del mantenimiento de la desigualdad en la vida cotidiana. Los denomina "micromachismos", no por minimizar la importancia de sus efectos en las mujeres, sino para resaltar su poca visualización y detección.

${ }^{10}$ Que los varones incorporen aspectos considerados femeninos dentro de su contexto, puede ser en otros casos un franco desafío a la normativa dominante masculina. El travestismo y la transexualidad, son dos ejemplos claros de irrupción de realidades que hacen trastabillar la "estabilidad" del mecanismo normativo dicotómico heterosexual que insiste en mantener dividido y con fronteras claras lo designado para mujeres y lo designado para hombres.

11 Para esta definición donde nos interesa resaltar el papel de la afectividad en la conformación de prácticas, nos ha sido útil la idea de "interpretante" retomado de la perspectiva semiótica de Peirce (1978). En especial, nos parece interesante el concepto de "interpretante emocional", definido como parte del efecto que dejan las emociones en la experiencia del sujeto, siendo también éstas al mismo tiempo, condición de posibilidad de generar efectos en el otro. Para Peirce este componente formaría parte de lo que se sedimenta en forma de hábito en el sujeto, lo que nos permite resaltar el carácter instituyente de las emociones en las prácticas de los sujetos. Por otra parte, para nuestra definición de responsabilidad aproximativa es importante mencionar que ésta se gesta en el marco de las relaciones cotidianas. Para White y Epston (1993) la interacción es la condición para que se generen visiones alternativas de entender y dar cuenta de nuestra vida en contraste con las visiones estrechas y delimitadas que establece la dominación. La interacción, el diálogo, son la condición del surgimiento de lo que él denomina "contraprácticas". En este mismo sentido, el concepto "zona de desarrollo próximo" de Vygotsky (1995), si bien está construido para otro tipo de análisis, nos es útil porque epistemológicamente coincide en otorgar importancia al encuentro entre sujetos para las trasformaciones mutuas, como escenario idóneo para el diálogo y ruptura de visiones 
individualistas. Para este autor, los cambios y aprendizajes en las experiencias se gestan de manera compartida, donde es fundamental el otro(a) cotidiano en este proceso.

12 Gergen (1996) nos recuerda que las emociones están presentes y no pueden separarse del ámbito de la evaluación moral.

${ }^{13}$ La ética discursiva en las que se inscriben Otto Apel (1991), Habermas (2002), Cortina (2000), permite sustentar que el diálogo forma parte de los escenarios que desafían los procesos de dominación. Si bien no negamos que posiciones de esta corriente, como la que sostiene Cortina, supone que para el diálogo se partiría de una posición idealizada de los sujetos, sí nos parece oportuna para explicitar, por una parte, la importancia del diálogo como mecanismo para hacer frente a la opresión, y por otra, el marco ideológico en el que nos movemos: igualitario, democrático, dialógico, marcado por la promoción y respeto de los derechos humanos; horizonte donde los sujetos tienen validez para legitimar y deslegitimar prácticas.

14 El silencio emocional además aleja a una relación de ser analizada desde procesos discursivos, morales e institucionales más amplios que nos permitan identificar de qué manera influyen y constriñen nuestros hábitos y prácticas cotidianas. En este sentido, Schreiter (1998) afirma que quienes suelen tener más elementos para enfrentar dinámicas de opresión son aquellos sujetos que logran colocar sus discursos y relatos personales en relación a otros discursos de un nivel más macrosocial y globalizante.

\section{References}

Amuchástegui, A. (2003). No sé decirles si quedó embarazada En J. Olavarría (Ed.), Varones adolescentes: género, identidades y sexualidades en América Latina (pp. 143-152). Santiago de Chile: FLACSO- Chile.

Apel, K. (1991). Teoría de la verdad y ética del discurso. Barcelona: Paidós.

Bajtín, M. (1982). Estética de la creación verbal. México: Siglo XXI. Bajtín, M., \& Volóshinov, V. (1992). El marxismo y la filosofía del lenguaje. Madrid: Alianza.

Bonino, L. (1995). Desvelando los micromachismos en la vida conyugal.

En J. Corsi (Ed.), Violencia masculina en la pareja. Argentina: Paidós.

Bonino, L. (2012). Discusiones sobre masculinidad. Seminario de análisis en el Centro de Estudios de la Condición Masculina. Madrid, España. Bowker, L. (1998). Masculinities and violence. London: Sage Publications. 
60 Botello-Análisis del "Enojo" del Varón

Bruner, J. (1986). Actual minds, posible worlds. Cambridge, MA: Harvard University Press.

Butler, J. (2001). El género en disputa. México: Paidós.

Connell, R. (2003). Masculinidades. México: Universidad Nacional Autónoma de México.

Cortina, A. (2000). Ética sin moral. Madrid: Tecnos.

Emma, L. (2005). Del sujeto a la agencia. Un análisis psicosocial de la acción política. Tesis de doctorado no publicada. España, Universidad Complutense de Madrid.

Enciso, D., \& Lara, A. (2014). Emociones y ciencias sociales en el s. XX: La precuela del giro afectivo. Athenea Digital, 14(1), 263-288. doi: $10.5565 / \mathrm{rev} /$ athenead/v14n1.1094

Gardner, H. (2001). Estructuras de la mente. La teoría de las inteligencias múltiples. Colombia: Fondo de Cultura Económica.

Gergen, K. (1996). Realidades y relaciones. Aproximaciones a la construcción social. Barcelona: Paidós.

Gilligan, C. (1982). In a different voice: psychological theory and women's development. Cambridge, MA: Harvard University Press.

Habermas, J. (2002). Teoría de la acción comunicativa I. México: Taurus.

Hansberg, O. (1996). La diversidad de las emociones. México: Fondo de Cultura Económica.

Hume, D. (2004). Disertación sobre las pasiones. Barcelona: Anthropos Editorial.

Ibáñez, T. (1994) Psicología social Construccionista. Guadalajara:

Universidad de Guadalajara.

Illouz, E. (2007). Intimidades congeladas. Las emociones en el capitalismo. España: Katz Editores.

Kaufman, M. (1989). Hombres, placer, poder y cambio. República Dominicana: CIPAF.

Kimmel, M. (1992). La producción teórica sobre la masculinidad: nuevos aportes. En R. Rodríguez (Ed.) Fin de siglo: género y cambio civilizatorio (pp. 129-138). Santiago de Chile: ISIS Internacional.

Kimmel, M. (1997). La masculinidad como homofobia: miedo, vergüenza y dolor. En T. Valdés \& J. Olavarría (Eds.), Masculinidad/es. Poder y crisis (pp. 49-62). Santiago de Chile: ISIS Internacional. 
Le Breton, D. (2012). Por una Antropología de las emociones. Estudios sobre Cuerpos, Emociones y Sociedad, 10(4), 69-79. Recuperado de http://www.relaces.com.ar/index.php/relaces/article/viewFile/208/14 5

Montague, A. (1988). Growing Young. New York: McGraw-Hill. Peirce, C. (1978). Lecciones sobre el Pragmatismo. Madrid: Aguilar. Potter, J. (1998). La representación de la realidad. Discurso, retórica y construcción social. Barcelona: Paidós.

Ramírez, G. (2001). Antropología “compleja” de las emociones humanas.

Isegoría, 25, 177-200. Recuperado de

http://isegoria.revistas.csic.es/index.php/isegoria/article/viewFile/589 1589

Ramírez, J., Gutiérrez, N., \& Cázares, L. (2015). Building a Public Policy Agenda Gender of Men in Mexico: Prolegomenon. Masculinities and Social Change,4(2),186-210. doi: 10.17583/msc.2015.1514

Schreiter, R. (1998). Violencia y reconciliación. España: Sal Terrae.

Seidler, V. (2000). La sinrazón masculina. Masculinidad y teoría social.

México: Universidad Nacional Autónoma de México.

Vigotsky, L. (1995). Historia del desarrollo de las funciones psíquicas superiores. Madrid: Aprendizaje Visor.

White, M., \& Epston, D. (1993). Medios narrativos para fines terapéuticos. Barcelona: Paidós.

Luis Botello Lonngi es Profesor Investigador en el Departamento de Educación y Comunicación de la Universidad Autónoma Metropolitana, México.

Contact Address: Direct correspondence to Luis Botello Lonngi, Prol. Canal de Miramontes 3855, Tlalpan, Ex Hacienda San Juan de Dios, 14387 Ciudad de México, CDMX, México email:

lbotellol@hotmail.com 